\title{
Residual Strain in Welded Joint of Pre-Strained Steel Plate
}

\author{
Ignatius Henry Adi Nagoro \\ Mechanical Engineering, Sebelas Maret University, Jl. Ir. Sutami 36 A \\ Surakarta, 57131, Indonesia \\ Triyono \\ Correspondence author, Mechanical Engineering Department, Jl. Ir. Sutami 36 A \\ Surakarta, 57131, Indonesia \\ E-mail:triyonomesin@uns.ac.id \\ M. Refai Muslih \\ Neutron Scattering Lab, Center forTechnology of Nuclear Industrial Materials (BATAN), Jl. Raya Serpong \\ Tangerang Selatan, 15314, Indonesia \\ Nurul Muhayat \\ Mechanical Engineering Department, Sebelas Maret University, \\ Jl. Ir. Sutami 36A Surakarta, 57131, Indonesia.
}

\begin{abstract}
The measurement of internal residual strain on the elastic, yield and plastic pre-strained of SS400 during welding had been performed using neutron diffraction technique. SS400 steel has been welded using gas metal arc welding (GMAW) in pre-strained condition of $0 \%, 1 \%, 3 \%$, and $5 \%$. This paper will present strength of welded joint increases with increasing pre-strain, and also theinformation regarding the residual strain profiles along of steel plate welded, obtained by determining the strain-free lattice spacing.
\end{abstract}

Keywords: Welding Distortion, Pre-strain, Residual Stress, Carbon Steel, Neutron Difraction.

\section{Introduction}

Angular, buckling, longitudinal ${ }^{1}$ are easily induced in welding structure because of gradient temperature in the weld plate, thus causing non-uniform expansion. Many methods have been studied to prevent this welding distortion. elastic analysis using the inherent strain method, constraint method $^{2}$,transient thermal tensioning method $^{3}$, pre-strain method ${ }^{4}$, and pre-tensioning method ${ }^{5}$. This paper studied pre-strain method to reducing welding distortion. With induced $0 \%, 1 \%, 3 \%$, and $5 \%$ of uniaxial tensile strain in the sheet metal then get start to welded.Essentially, the pre-strain causes a change in micro-structural alternation and yields variations in various mechanic behaviors. So, several related journals can be used as basic to aquire knowledgeon the effect of pre-strain on the residual strain of the weld joints. For some materials ${ }^{4}$, has been found that pre-strain can increasedthehardness, yield strength, andtensile strength, butitlowersthe percentage ofelongation. In hot rolled sheet plate, Ghosh et. al. ${ }^{6}$ was found that creep strain rate and greater ductility when compared to AISI316 is undergoing a process of annealing. The other method $^{3}$ using a thermo-elastic-plastic analysis verified that to model welding in the state of transient thermal tensioning minimizes buckling distortion due to welding by redusing the welding residual stress. Residual stresses is known affect to both of initiation and growth stages of 
fatigue cracks, through changes to the effective mean stress experienced during fatigue cycling. When 5053H321 aluminium plates welded using double pass of FSW, using synchrotron radiation technique James etal. ${ }^{7}$ was found that effect of fatiguebending loading, a significantly increase thepeak of tensile and compressiveresidual stress also translation of theresidual stress field to the tensile side. In spot welding, using neutron diffraction technique Suzuki et $\mathrm{al}^{8}$ also found where a fatigue fracture occured, on the majority of residual stress near the center of weld.

In order to measure the residual strain distribution, non desstructive method using X-rays, Synchroton radiation, or neutrons is generally applied. But, only neutron beam wich can establish stresses in the interior of components of metalic material and have small volume of measurement $\left(1 \mathrm{~mm}^{3}\right)^{9}$.Therefore, when fillet welding is performed with pre-strain, neutron diffraction technique is possible to illustrate the effect of pre-strain level on the distribution of residual stress.

\section{Experimental Method}

\subsection{Materials and welding procedure}

The material used in this study was low carbon steel plates. The chemical composition of steels has determined using absorber atom spectrometeris show in table 1. Representative sspecimens from steel sheets (of 4,6 mm thickness) were cut of $12,5 \mathrm{~mm}$ width and 50 mm gauge length following ASTM standard E8M-00 (ASTM 2003) for tensile tests ( $0 \%$ pre-strain). These test were carried out with universal testing machine at the room temperature of approximately $300 \mathrm{~K}$. The sequential displacement of specimens is used to calculate the strain values.

Table 1. Chemical composition of the low carbon steel (in wt $\%$ )

\begin{tabular}{llllllll}
\hline $\mathrm{C}$ & $\mathrm{Mn}$ & $\mathrm{Si}$ & $\mathrm{Ni}$ & $\mathrm{Cr}$ & $\mathrm{Mo}$ & $\mathrm{P}$ & $\mathrm{Fe}$ \\
\hline 0,06 & 0,282 & 0,005 & 0,175 & 0,05 & 0,08 & 0,024 & 98,8 \\
\hline
\end{tabular}

The base plates (length_width_thickness; 300mm _ 100mm_5mm) were mounted on hydrolic pre-strain machine, then pre-strained in $0 \% 1 \%, 3 \%$, and $5 \%$ prestrain level then get start to weld. The welding conditions are $140 \mathrm{~A}, 24 \mathrm{~V}$, and $390 \mathrm{~mm} / \mathrm{min}$, using Krisbow MIG 200 welding machine. The electrode was ER-70, 1,0mm in diameter with $20 \mathrm{~mm}$ contact tip to work distance. The welds were made with argon gas with flow rates 15
$1 / \mathrm{min}$, The leg length is $3 \mathrm{~mm}$ and single fillet welds are deposites simultaneously on the one side of the joint.

\subsection{Determination of strength of fillet welding}

The strength of the fillet welds of pre-strained sheets (having $0 \%, 1 \%, 3 \%$, and $5 \%$ pre-strain was determine using 10 ton capacityservo-hydraulic universal testing machine (model: SHT 4106) using cross head velocity of $15 \mathrm{~mm} / \mathrm{min}$ at the room temperature of approximately $300 \mathrm{~K}$. The samples were tested following ASTM standard E8M-00 (ASTM 2003).

\subsection{Measurement of residual strain}

Measurement of residual strain had been performed using neutron diffractometer for residual stress measurement DN1. DN1 attached to tangential beam tube S6 of Indonesianmultipurpose reactor RSG-GAS at Serpong. Thanks to superiority of neutron penetration power, the measurement of interior residual stress could be performed non destructively. 2-D detector had been installed at DN1, recently. This new detector made measurement time shorter, with image of the diffracted neutrons displayed in real-time.

Solid materials may be classified according to the regularity with which atoms or ions are arranged with respect to one another. A crystalline material is one in which the atoms are situated in a repeating or periodic array over large atomic distances; that is, long-range order exists, such that upon solidification, the atoms will position themselves in a repetitive three-dimensional pattern, in which each atom is bonded to its nearestneighbor atoms. The diffraction peak gives the average of the strain in the different types of grains present in gauge volume. So, the response of diffraction peak for every crystallographic may be different. During the experiment, residual strainswere measured using (110) deflection, the wavelength of neutron beam used was approximately $1,836 \AA$, and diffraction angle $2 \theta$ was set $90^{\circ}$. The incident slit was used $3 \mathrm{~mm} \times 3 \mathrm{~mm}$ slit, and $3 \mathrm{~mm}$ radial collimator was used as receiving slit. The measurement set-up used is shown in Fig. 1. Residual strain was measured at intervals of $0 \mathrm{~mm}, 3 \mathrm{~mm}, 8 \mathrm{~mm}$, $18 \mathrm{~mm}, 28 \mathrm{~mm}$ start from the fillet welds only in longitudinal direction. Because, in welded samples the most stress gradients was affected this direction.

Diffraction can be used to precisely measure a lattice spacing utilizing Bragg's law: 


$$
\lambda=2 d \sin \theta(1)
$$

Here, $\lambda$ is the wavelength of the radiation used, $\theta$ is one-half the scattering angle, and $d$ is the average interplanar spacing for a given reflection in a crystalline material. In a stressed material, the lattice spacing can be used as a strain gauge, giving a measure of linear strain in the direction of the diffraction vector. If $d_{0}$ and $\theta_{0}$ are the lattice spacing and the corresponding Bragg angle measured for the stress-free material, the strain can be computed as:

$$
\varepsilon=\frac{d-d_{0}}{d_{0}}
$$

The state of strain at some location in a material is a second-order tensor quantity represented by shear and normal components referenced to a given coordinate system. We can determine the state of strain in a material using diffraction by measuring the linear or normal strain in a number of directions and utilizing the rules specifying how the components of a secondorder tensor transform with direction.
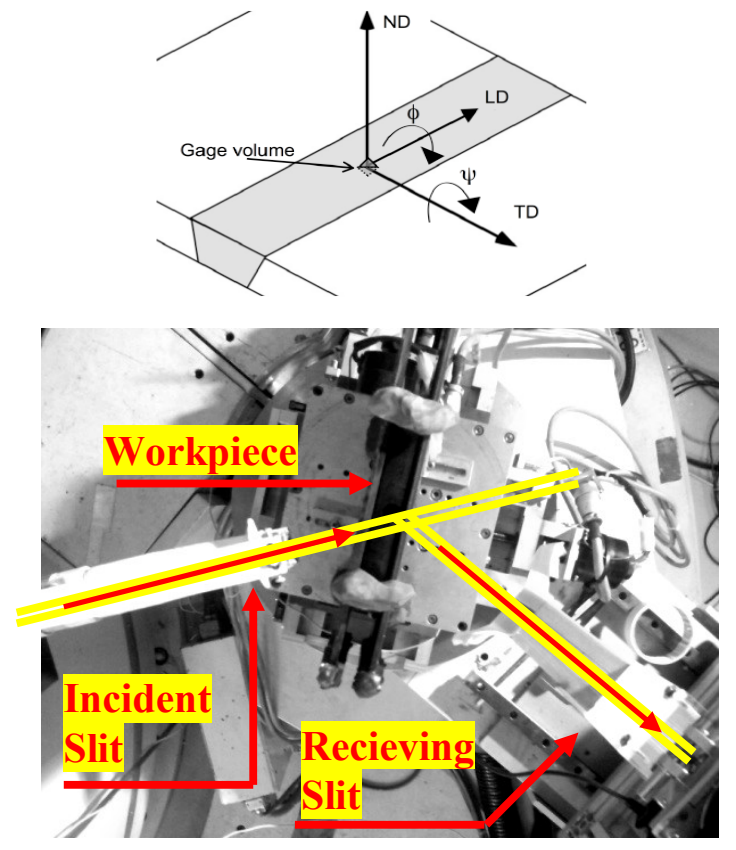

Fig. 1. Gauge volume in strain scanning method

\section{Experimental Result}

\subsection{Tensile Properties}

Typical microstructures of steels areshown in Fig. 2. Which exhibit predominantly equiaxed ferrite. Fig. 3 are shown curve of the engineering stress-strain for the pre- strained steel. The strength value and ductility of the $1 \%$ and 3\% pre-strained steel are increased while in $5 \%$ of pre-strain the strength value is reduced.

Increasing strength of pre-strained sheets is happen because of work-hardening thus increase dislocation density. Furthermore, microstructural evolution during annealing also associated with developmentultrafinegrained structure. ${ }^{7}$ which is more dense, so it can increase the hardness value. ${ }^{4}$ and the resistance to deformation. ${ }^{56}$ Muchopadhay et al. ${ }^{4}$ was also found the same thing, that pre-strain can increase the strength of material.

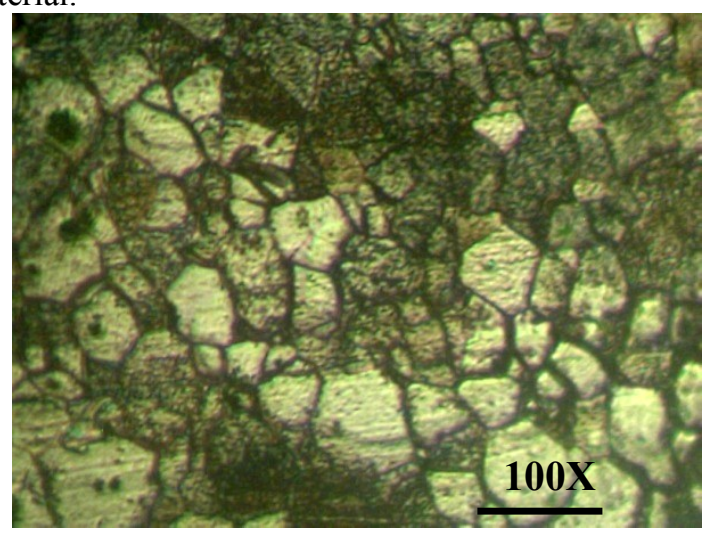

Fig. 2. microstructure of base metal SS400 in longitudinal direction in rolling

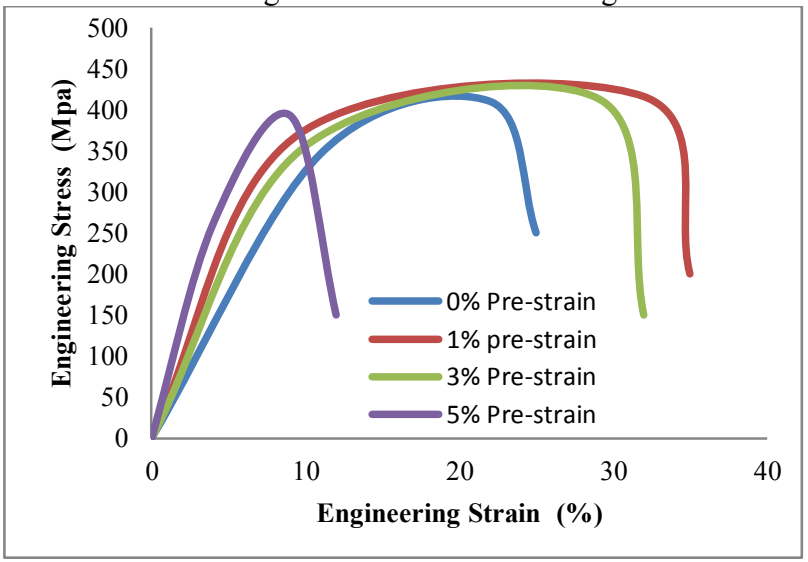

Fig. 3. Engineering stress-strain curve of steel plate welded which is pre-strained at different level

Fig 4 illustrates the structural changes leading to the development submicrocrystaline structures in heat affected zone (HAZ) area. Increasing dislocation density during deformation promotes deformation twining thus provide strain herdening in the pre-strain rates $1 \%$ and $3 \%$. 


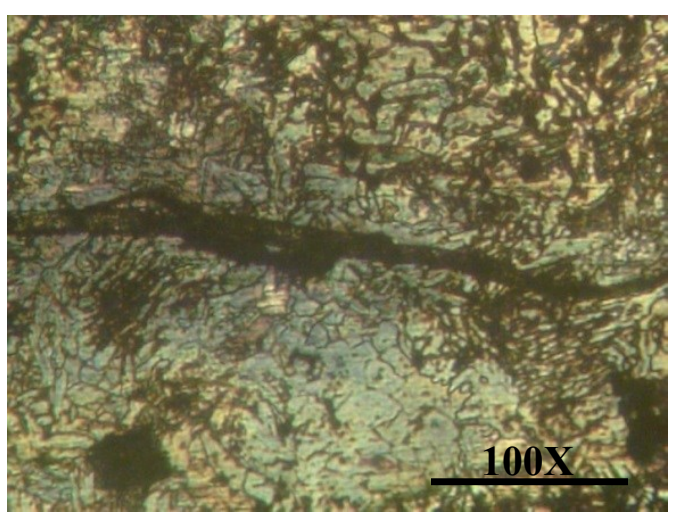

Fig 4.shape of annealed microstructure in HAZ area

\subsection{Cross-section structure}

In this experiment, the point of residual strain measurement by the neutron diffraction method is shown in Fig. 5. Longitudinal direction strain were measured at the middle thickness of specimen.

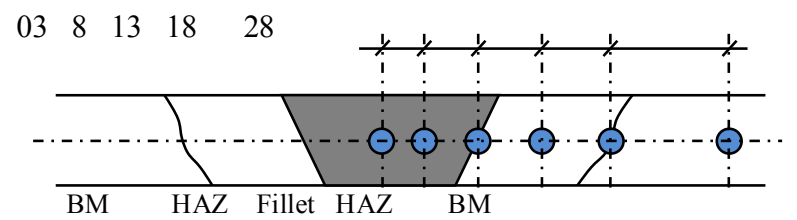

Fig. 5. Cross-section of residual strain measurement

The diffraction profile was determined by the peak position using general-purpose Gaussian fitting ${ }^{8}$. An neutron example of diffraction profile and the fitting curve is shown in Fig. 6.
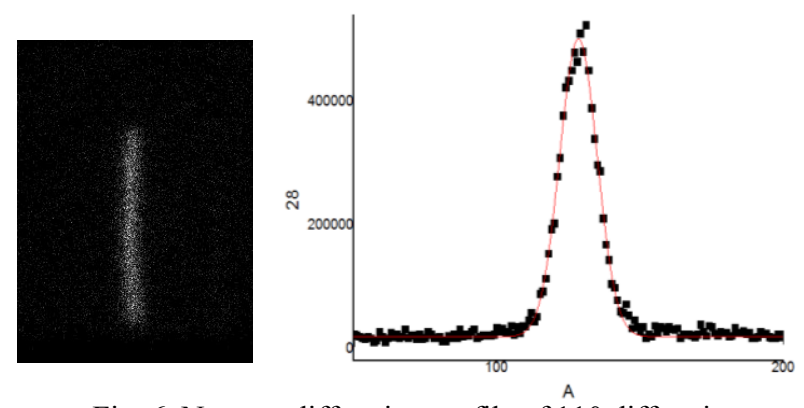

Fig. 6. Neutron diffraction profile of 110 diffraction (X axis $=2$ Theta, $\mathrm{Y}$ axis Counts/....sec.)

To calibrate the elastic strain $\varepsilon$, a stress-free reference in diffraction angle $2 \theta$ is required. In order to relax residual stress, the base metal in dimension $50 \mathrm{~mm} \mathrm{x}$ $50 \mathrm{~mm} \times 4,6 \mathrm{~mm}$ were cut by EDM. The measurement was done with DN1 instrument using incident slit $0,1 \times 10$ $\mathrm{mm}^{2}$ and radial collimator. Scanning $2 \theta$ was $0.2^{0}$ start from $0^{0}$ to $-2^{0}$ with measurement time 5 second for each step. The result was indicate that value of stress free from base metal is 128,475 .

The experiment result is shown in Fig. 7. It can be seen that at any point of measurement, stress distribution in the vicinity of pre-strained $1 \%, 3 \%$, and $5 \%$ the are almost same. Which is, largest residual stress occurred in center of the weld, then decreases until reach the base metal area. This mechanism occurs because of microstructural evolution during the annealing thus development ultrafine-microstrusture as shown in Fig. 4. This result is same as the fracture location of tensile test specimen, which shown initially of crack are propagated in the base metal.

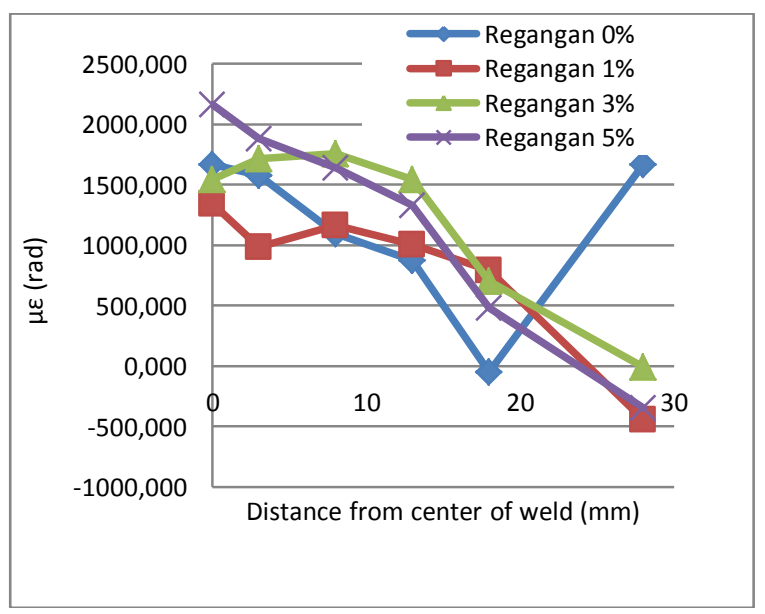

Fig. 7. Residual strain distribution from fusion line to base metal

\section{Conclusion}

Combines the mechanical testing of materials with neutron diffraction method was done to know residual strain distribution caused by weld with pre-strain applied. From this experiment and their analyses lead to following conclusions :

1. The strength of steel plate increases with increasing pre-strain on base metal. It's happen because of work hardening and annealing process thus increase dislocation density then development iltrafinegrained structure.

2. Pre-strain has been prove decrease residual strain in steel plates, it's happen because of microstructure evolution during annealing.

3. Experimental result show that pre-strain in made welding residual strain decrease by $20 \%$ on $1 \%$ prestrain and $8 \%$ on $3 \%$ pre-strain. 


\section{Acknowledgments}

Authors would like to express their sincere gratitude to SebelasMaret University, Surakarta for financial support rendered through PNBP 2014 grant with contract no. 501/UN27.11/PN/2014.

\section{References}

1. Masubuchi K. Analysis of Welded Structures. (Oxford, Pergamon Press, 1980).

2. Murakawa H, Luo Y, Ueda Y. Prediction of Welding Deformation and Residual Stress by Elastic FEM Based on Inherent Strain (first report) - Mechanism of Inherent Strain Production. (Trans Soc Naval Arch Jpn 1996, 180, 739-51).

3. P.Michaleris, J.dantzigand, D.tortorelli. Minimization of Welding Residual Stress and Distortion in Large Structure. (AWS Nov 1999, 361-366).

4. G.Mukhopadhyay, S.Bhattacharya, K.K. Ray. Effect of Pre-strain on the Strength of Spot-welds. (Elsevier 2009, 30, 2345-2354).

5. Jeong-Ung Park, Gyubaek An, Hae-Woo lee. Effect of External Load on Angular Distortion in Fillet Welding. (Elsevier 2012, 42, 403-410).

6. S K Ghost, P Mallick, P P Chattopadhyay, Effect of Cold Deformation on Phase Evolution and Mechanical Properties in an Austenitic Stainless Steel for Structural and Safety Applications. (Journal of Iron and Steel Research, International 2012, 19(4), 63-68).

7. M.N. James, D.J. Hughes, Z.Chen, H.Lombard, D.G. hattingh, D. Asquith, J.R. Yates, P. J. Webster, Residual Stresses and Fatigue Performance. (Elsevier, Engineering Failure Analysis 14 (2007), 384-395).

8. Tamaki Suzuki, Hatsuiko Oikawa, Muneyuki Imafuku, Hiroshi Suzuki, Masaaki Sugiyama, tetsuro Nose, Yo Tomota, Atsushi Morai. Residual Stresss Measurement of Welding Area by Neutron Diffraction Method. (Nippon Steel Technical report No. 100 July 2011).

9. C. Acevedo, A. Evans, A. Nussbaumer. Neutron Diffraction Investigations on Residual Stresses Contributing to the Fatigue Crack Growth in Ferritic Steel Tubular Bridges. (Elsevier 2012, 1-8).

10. Kim JH, Barlat F, Kim CM, Chung KS. Thermomechanical and Microstructural Modeling of Friction Stir Welding of 6111-T4 Aluminum Alloys. (Met Mater Int 2009, 15, 125-32).

11. Bang KS, Park C, Jung HC, Lee JB. Effects of Flux Composition on the Element Transfer and Mechanical Properties of Weld Metal in Submerged Arc Welding. (Met Mater Int 2009, 15, 471-7).

12. Wang R, Zhang J, Serizawa H, Murakawa H. Study of Welding Inherent Deformations in Thin Plates Based on Finite Element Analysis Using Interactive Substructure Method. (Mater Des 2009, 30, 3474-8).

13. Wang J, Ma N, Murakawa H, Teng B, Yuan S. Prediction and Measurement of Welding Distortion of a Spherical Structure Assembled From Multi Thin Plates. (Mater Des 2011, 32, 4728-37).
14. Yung-Chuan Chiou, Jen-KangYang. The Effect of PreDeformation on the Subsequent Fatigue Behaviors of SUS 430 Stainless Steel in Load Control. (Elsevier 2012).

15. Standard Test Methods For Tension Testing of Metallic Materials (Metric). (ASTM E8M-03, 2003). 